\title{
Some aspects of using blockchain in supply chain management in the framework of achieving sustainable development goals
}

\author{
Nurlan Kozhanov ${ }^{1}$, and Dr. Fabbian Woebbeking ${ }^{2}$ \\ ${ }^{1}$ Novosibirsk State Technical University, Karl Marx Avenue, 20, 630073 Novosibirsk, Russia \\ ${ }^{2}$ Frankfurt School of Finance and Management, Adickesallee 32-34, 60322 Frankfurt am Main, \\ Germany
}

\begin{abstract}
The practical implementation of sustainable development outlined in Agenda 2030 requires the appliance of effective tools. In the context of global digital management, blockchain technology which is now actively used in logistics and supply chain management, can serve as such. The article highlights some of the benefits of blockchain technology for achieving sustainable development goals. The blockchain technology itself is briefly described. Examples of the use of blockchain technology in various elements of supply chain management are presented.
\end{abstract}

\section{Introduction}

In recent decades, globalization and internationalization of world economic relations has exerted strong pressure on all aspects of the activities of economic entities around the world. These processes are accompanied by the explosive growth of technologies, tectonic shifts in the social sphere and an unprecedented tension of competitive confrontation.

Being drawn into the discouraging race for competitive advantage, humanity began to make not always well-conceived, often irresponsible decisions in the field of interaction with the outside world. Neither countries with a high level of industrial development, nor developing countries of the "third world" wanted to abandon the development paradigm based on economic growth, at the expense of environmental welfare.

The second half of the twentieth century clearly showed that environmental and related socio-economic problems such as desertification, difficulties accessing clean drinking water, increasing poverty in countries, predatory destruction of forests, threat to biodiversity and the greenhouse effect - can no longer be ignored.

The outlines of the ecological catastrophe began to develop with frightening realism. More and more people worldwide began to realize not only the unacceptability of such models of economic growth, but also the need to harmonize the goals of economic development with ecological balance.

The starting point in this process was the report "Our Common Future", prepared by the Brundtland Commission in 1987. The stumbling block was the confrontation between economics and ecology. The means to achieve the goals of economic well-being became 
more and more destructive to the environment, which posed a threat to the very existence of civilization.

The Report attempted a systematic approach to resolving this contradiction. Brundtlandil's Commission proposed to the global community to change the emphasis from economic development to sustainable development, under which the needs of the present generation are should be met without the damage to the possibilities of the future to meet their own needs [1].

In fact, the world community began to take purposeful and systematic steps to overcome the problems that had risen, precisely after the proclamation of the idea of "sustainable development" from the rostrum of the UN General Assembly.

However, on the threshold of the 21 st century, new challenges have been added, including issues such as digital sovereignty and digital vulnerability, carbon neutrality and cybercrime, and many others. In response to these new challenges, the structure of the UN system for sustainable development for the period up to 2030 (Agenda 2030), adopted in 2015 by 193 UN member states, has defined the Sustainable Development Goals (SDGs) for the world community at the present stage. The 17 global goals and 196 tasks proposed in Agenda 2030 clearly demonstrate both the seriousness of the new problems and the seriousness of the world community to overcome them [2].

All these phenomena clearly show us that the world community is now rapidly plunging into the turbulent waters of the global digital revolution, and the world economy is in the whirlpool of a new spin of the fourth industrial revolution. The driving force behind these revolutionary converters is digital technology - both existing and currently emerging.

Machine learning, artificial intelligence, the internet of things, augmented reality, blockchain and many other names for digital technologies have burst into our analogue reality and painlessly implanted not only in the economic, but also in everyday vocabulary.

Some of these technologies look pretentiously futuristic and there is a huge skepticism about their implementation, others, on the contrary, not only took root in our vocabulary, but we can already say with confidence, become reliable assistants in solving everyday, routine, yet difficult tasks. One of these technologies is blockchain.

\section{Blockchain and Sustainable Development Goals}

The word blockchain can be translated from English as "a chain of blocks". However, the translation of this term to Russian conveys the essence of this phenomenon with difficulty.

The concept of a blockchain is based on the idea of such a database, whose information is dispersed among a number of independent from each other mediums - computers.

These exact computers, which store the entered information, are precisely the constituent elements - "blocks". In each such block, a certain category of data on the operations performed by the network users is entered and stored.

All this set of independent from each other computers, is a gigantic repository of all user operations' copies. As a result, new operations generate the creation of new blocks, which store the headline and a list of operations performed in a certain time.

After a new block is generated, other network users verify it. In case when all the participants agree unanimously, i.e. if none of the reviewers questions the authenticity of the information in the new block, it is included in the chain. Then, the database is updated automatically on all devices connected to the network. And from that moment on, no manipulations (making amendments, adjustments, additions, etc.) are possible within it [3].

In addition, the new block, apart from the actual information, can have encoded data contained in the previous blocks, and together they create an up-to-date history of all operations within the network. 
Traditionally, the blockchain is associated with bitcoin. This is due to the fact that the technology received wide publicity in 2008 , when a person or group of people, under the pseudonym Satoshi Nakamoto, announced a decentralized network of electronic money called bitcoin. But the blockchain technology itself was developed in 1991 by S. Haber and W. Scott Shtornetta. The idea behind their discovery was to process digital documents with a time stamp, which excluded the possibility of their falsification or retroactive design. However, at that time, their idea did not receive wide interest, and the authors did not even patent it [4].

What are the benefits of this technology and how might they impact the Sustainable Development Goals? First, the distribution. As you know, information about various types of transactions (purchase of equipment, obtaining a loan, services payment, etc.) is stored on the servers of the participants in such operations. Practice shows that the existing security systems, unfortunately, do not always adequately respond to modern cyber threats and allow criminals an unauthorized access to confidential information.

Cybercrime is one of the most significant threats to the sustainable development principles. The global economy annually loses about USD 600 billion, or $0.8 \%$ of world GDP, due to cyberspace crimes, and the annual losses of the Russian economy amount to more than RUB 600 billion (about 1\% of GDP). The seriousness of the situation is confirmed by international initiatives designed to stop the problems with cybercrime and create conditions for the sustainable development of cyberspace.

The most famous initiative is the Paris Call for Trust and Security, a declaration announced in 2018 by French President E. Macron, calling for the development of general principles to ensure trust and security on the Internet. 78 countries, 346 public organizations and more than 640 companies have joined the declaration. And the UN Resolution to Combat Cybercrime - adopted by the UN General Assembly in 2019, supported by 79 countries. Russia was one of the initiators and co-authors of the resolution [5].

Since blockchain technology encompasses for the storage of data on a huge number of computers scattered around the world, it is simply not possible to "hack" them all. One working computer is enough for the system to continue functioning.

Secondly, digital security. One of the essential priorities in achieving sustainable development goals is security as an integral part of human rights. Today, there is hardly a website or application that does not collect various information about its users. This is not surprising, because almost every user, registering in online stores or downloading the applications he needs, leaves certain data about him.

It is possible that there is nothing reprehensible in the fact that Telecommunications- and Internet-companies, financial institutions and the State collect data about us, however, due to various circumstances, ranging from direct attacks by hackers to banal negligence of operators, personal data of users turns out to be public or worse, ends up in the hands of wrongdoers.

And today we are talking not only about the personal data of individual users, but also about the entire organizations. Everyone became vulnerable! As a result of data leaks, about 170 million accounts were compromised in Russia in 2019. The number of such leaks in Russia over the same year increased by $40 \%$ (in the world by $10 \%$ ) [5].

In order to compromise data, attackers must gain access directly to one or several blocks. However, in blockchain this is not possible. As already mentioned, data is stored on a huge variety of computers around the world and in order to make any changes, you need to hack all of them, as well as database backups. It is even hard to imagine what kind of computing power will be required for this!

In addition, an encryption algorithm using hash functions and digital signatures is responsible for the security of information. A hash function is a set of arbitrary characters that guarantees the invariability of all recorded information. And digital signatures use keys 
- private (for creation) and open (for verification). It is with the help of these keys that users gain access to information. Thus, the operation of the network is entirely based on mathematical calculations, and not on trust relationships between its participants.

Thirdly, the transparency. Free access to databases allows any user to get acquainted with the information. Any interested party can get access to the study of data on any transaction, up to the personal data of the participants. Of course, provided that this data is open by the participants themselves.

Fourthly - minimizing the need for intermediaries. Today banks, electronic payment systems, insurers, lawyers, etc. take part in any financial transactions. Often, such operations are delayed in time or even blocked, due to the fact that some of the intermediaries have doubts about this transaction. And one has to put up with it. However, blockchain technology provides a unique opportunity for direct information exchange, in which only users of the system are involved in confirming transactions.

The fact that the United Nations Organization (UN) uses this technology can serve as a convincing proof of the blockchain reliability. Relatively recently, the UN was awarded the inclusion in the Blockchain 50 list by Forbes [6], for its significant contribution to the use of this technology.

UN Secretary-General António Guterres said in an interview that for the United Nations to better fulfill its mandate in the digital age, it must use technologies such as blockchain that can help accelerate the achievement of sustainable development goals.

In our prespective, this is quite a logical result for an organization whose secretarygeneral in 2012 openly admitted that 30 percent of all UN financial assistance for development was lost due to the actions of wrongdoers and opaque financial schemes. Special Advisor for UN Engagement and Blockchain Technology at United Nations Office for Project Services (UNOPS) Yoshiyuki Yamamoto said that if we do not know where 30 percent of the money is, then this is a big problem for everyone.

All these advantages have attracted not only UN specialists, but also specialists in the field of logistics and supply chain management.

\section{Blockchain and supply chain management}

How can blockchain technology be useful for logistics and supply chain management? First, by the creation of a unified cargo tracking system. The discrete nature of logistics operations is clearly visible in the use of accounting systems, such as, for example, ERP. The advantages of a corporate resource planning system become especially evident in international logistics operations, which involve contractors from different countries and use all types of transportation (sea, land and air).

However, the problem is that participants in international supply chains use different accounting systems. As a result, logisticians are forced to carry out communications in an "analog" format: paper media, faxes, couriers, personal meetings. The main disadvantage of this approach is that some of the goods and vehicles are either lost or idle, as they "fall out" of sight of diverse accounting systems, while the elimination of system inconsistencies requires the use of additional resources - both temporary and financial.

By utilizing blockchain technology, it became possible to create a globally stable, consolidated workflow system in a standardized digital format that will allow real-time monitoring of the movement of goods and vehicles. The "cloud storage" technology can serve as a platform for such a system.

This approach is already practiced by world-famous giants of the retail industry, such as Walmart, Nestle, and Unilever. The latter applies the Provenance blockchain in tea supply chain management. This blockchain project includes several thousand farmers, many financial and credit institutions, a large number of small retailers and transport companies. 
Such projects are a good foundation for the implementation of the global Sustainable Development Goals, which proclaim the availability of "high quality, relevant and reliable data disaggregated by income level, gender, age, race, nationality, migration status, disability, geographic location and other significant characteristics with consideration to national conditions".

Secondly, blockchain technology is useful for logistics and supply chain management by the creation of a quality and authenticity control system. According to experts, the market for counterfeit products in the world reaches a colossal amount of 461 billion US dollars [7]. This figure can be compared, for example, with the GDP of Austria or Belgium.

According to the UN, the damage from various economic crimes, which certainly include the production and sale of counterfeit products, only in the developing countries can reach 1.26 trillion US dollars. By comparison, this amount would be enough to raise the standard of living of those living on less than $1.25 \$$ a day by as much as six years [8]. This state of affairs is clearly contrary to the principles and spirit of the Sustainable Development Goals.

In the struggle to prevent the creation of counterfeit products and to confirm the authenticity of the origin of products, blockchain technology demonstrates its high efficiency. A good example of how blockchain technology can effectively achieve a result in such a difficult situation is Nestle, which uses the IBM Food Trust blockchain platform for its coffee brand Zoegas [9].

By scanning the QR code on the packaging, consumers can trace the coffee's path through the entire supply chain from the production site to the Zoegas factory in Helsingborg, Sweden, where the beans are roasted, grounded and packed. The data includes information not only about the farmers and the time of harvest, but also about all the manipulations carried out with a particular batch of coffee, right down to the time of roasting.

As for the quality control system, first of all, we are talking about the damage to food products during transportation. The statistics are impressive in their size: food products alone are lost on average in the amount of about 1.2 trillion US dollars per year, $40 \%$ of them during transportation.

And this is in conditions when, according to the UN, almost 690 million people, or 8.9 percent of the world's population, are starving, which is an increase of 10 million people in one year and almost 60 million in five years [10]. Therefore, it is only natural that among the 17 Sustainable Development Goals, the goal of ending hunger, ensuring food security and improving nutrition, and promoting sustainable agricultural development is in the second place.

Blockchain technology contributes to achieving this goal, which makes it possible to resolve the issue of the quality of food transportation. This is achieved with the help of already well-proven technology, RFID tags and, relatively new, IoT sensors.

Integrated with the blockchain, both technologies allow tracing the path of goods from production to the counter and all manipulations along the route. In addition, both technologies allow monitoring of various technical characteristics of the movement of goods, for example - speed, humidity, temperature, etc. This helps prevent food spoilage during transportation.

It is not surprising that blockchain in this format is actively used by pharmaceutical industry enterprises. Thus, the American blockchain project MediLedger is designed to help the practical implementation of legislative initiatives that tighten control over pharmaceuticals by entering unique identifiers for each product unit.

And the Swiss company SkyCell, specializing in the production of hybrid containers for the pharmaceutical industry, has developed a promising freight container with an installed IoT sensor integrated with the blockchain through cloud storage technology. It allows you to continuously receive up-to-date information on the status of transported goods online.

Thirdly, via an improved freight and delivery system. IBM estimates that a typical delivery scenario could involve 10 to 30 participants who, in the process of delivering just 
one shipment, exchange more than 200 paper messages. And the cost of service is up to $15 \%$ of the shipping cost.

Thanks to the implementation of one of the most important applications of the blockchain smart contract technology, according to IBM, it will save more than 30 billion US dollars. IT giant IBM and global shipping company A.P. Moller-Maersk Group were among the first to use blockchain technology for supply tracking and supply chain management [11]. They launched a blockchain platform called TradeLens. According to some reports, at the moment TradeLens accounts for about $30 \%$ of the world shipping market.

\section{Conclusion}

Thus, blockchain as a new technology provides benefits to all participants in the supply chain in the form of saving resources and time in the implementation of practical activities. However, despite the active development of blockchain in such areas as telecommunications, financial and banking sectors, the possibilities, advantages and disadvantages of technology in relation to supply chain management are still poorly understood.

Today, there are a lot of conservative logistics enterprises in the world, in which there are a lot of manual operations, paper workflow and supra-contractual relations. They, for the most part, ineffectively manage their existing assets: for example, according to some estimates in the world, about $50 \%$ of the vehicles involved in cargo transportation, upon completing the task, return empty. It is this conservative ideology of building logistics activities that creates obstacles to the integration of digital technologies into logistics business processes.

All this is aggravated by the fact that both in the logistics community and beyond its framework, discussions continue about the prospects for using blockchain and other digitalization tools, about the possible risks and threats associated with the transition to digital technologies in supply chain management [12]. This indicates a lack of awareness and doubts among logistics professionals regarding both blockchain and other digital technologies.

Therefore, today the study and generalization of the experience of using blockchain in supply chain management and the use of blockchain platforms in global logistics is an important methodological task.

How fast blockchain technologies will develop is still unknown, but even today the use of blockchain in logistics and supply chain management guarantees the cybersecurity of databases and their protection from hacker attacks, as well as prevents unauthorized access to information about commercial processes within the supply chain.

The blockchain helps to reduce the costs of delivery of goods and negate the possibility of implementing fraudulent schemes even today, and also allows creating a unified cargo tracking system, a stable global document flow system, quality and authenticity control systems, and an improved freight and delivery system. In addition, the implementation of blockchain can become an effective tool for creating conditions for increasing competitiveness within the framework of the implementation of the Sustainable Development Goals outlined in the 2030 Agenda.

\section{References}

1. Report of the World Commission on Environment and Development (Brundtland Report), https://documents-dds-ny.un.org

2. UN General Assembly resolution. Transforming our world: The 2030 Agenda for Sustainable Development, https://web.archive.org

3. V. I. Sergeev, Logistics and supply chain management, 1, 96, (2020) 
4. Jessica Klein. Blockchain Pioneer W. Scott Stornetta Assesses Satoshi's Work. Breakermag, https://breakermag.com

5. Russia and Sustainable Digital Development. - The Russian Association for Electronic Communications (2020) https://raec.ru

6. Darryn Pollock. Blockchain For Good: How The United Nations Is Looking To Leverage Technology. - Forbes (2020) https://www.forbes.com

7. A. Petroff, The 'fakes' industry is worth $\$ 461$ billion. - Money.CNN (2016) https://money.cnn.com

8. United Nations Sustainable Development - 17 Goals to Transform Our World. Goal 16: Promote just, peaceful and inclusive societies. - United Nations (2021) https://www.un.org

9. Darryn Pollock. Nestle Expands Use Of IBM Food Trust Blockchain To Its Zoegas Coffee Brand. - Forbes (2020) https://www.forbes.com

10. United Nations Sustainable Development - 17 Goals to Transform Our World. Goal 2: Zero Hunger, https://www.un.org

11. Ian Allison. Maersk and IBM want 10 million shipping containers on the global supply block chain by year-end. - International Business Times (2017) https://www.ibtimes.co.uk

12. V. Maltseva, A. Maltsev. Blockchain and the Future of Global Trade (Review of the WTO report "Can Blockchain revolutionize international trade?"), International Organisations Research Journal, 14, 4 (2019) 